\title{
Association between internalized stigma and depression among HIV-positive persons entering into care in Southern India
}

\author{
Brian T Chan ${ }^{1,2}$, Amrose \\ Pradeep ${ }^{3}$, Lakshmi Prasad ${ }^{3}$, \\ Vinothini Murugesan ${ }^{3}$, Ezhilarasi \\ Chandrasekaran ${ }^{3}$, Nagalingeswaran \\ Kumarasamy ${ }^{3}$, Kenneth H Mayer ${ }^{2,4,5}$, \\ Alexander C Tsai ${ }^{2,6,7}$

\footnotetext{
${ }^{1}$ Division of Infectious Diseases, Brigham and USA

${ }^{3}$ Y. R. Gaitonde Centre for AIDS Research and Education, Chennai, India

${ }^{4}$ Division of Infectious Diseases, Beth Israel Deaconess Medical Center, Boston, Massachusetts, USA

${ }^{5}$ Fenway Health, Boston, Massachusetts, USA

${ }^{6}$ MGH Global Health, Massachusetts General Hospital, Boston, Massachusetts, USA

${ }^{7}$ Chester M. Pierce, MD Division of Global Psychiatry, Massachusetts General Hospital, Boston, Massachusetts, USA
} \\ Women's Hospital, Boston, Massachusetts, USA \\ ${ }^{2}$ Harvard Medical School, Boston, Massachusetts,
}

\begin{abstract}
Background In India, which has the third largest HIV epidemic in the world, depression and HIV-related stigma may contribute to high rates of poor HIV-related outcomes such as loss to care and lack of virologic suppression.

Methods We analyzed data from a large HIV treatment center in southern India to estimate the burden of depressive symptoms and internalized stigma among Indian people living with HIV (PLHIV) entering into HIV care and to test the hypothesis that probable depression was associated with internalized stigma. We fitted modified Poisson regression models, adjusted for sociodemographic variables, with probable depression (PHQ-9 score $\geq 10$ or recent suicidal thoughts) as the outcome variable and the Internalized AIDS-Related Stigma Scale (IARSS) score as the explanatory variable.
\end{abstract}

Findings 521 persons (304 men and 217 women) entering into HIV care between January 2015 and May 2016 were included in the analyses. The prevalence of probable depression was $10 \%$ and the mean IARSS score was 2.4 (out of 6), with $82 \%$ of participants endorsing at least one item on the IARSS. There was a nearly two times higher risk of probable depression for every additional point on the IARSS score (Adjusted Risk Ratio: 1.83; 95\% confidence interval, 1.56-2.14).

Conclusions Depression and internalized stigma are highly correlated among PLHIV entering into HIV care in southern India and may provide targets for policymakers seeking to improve HIV-related outcomes in India.

\section{Correspondence to:}

Brian T. Chan, MD, MPH

Brigham and Women's Hospital

15 Francis Street, PBBA-4

Boston, MA 02115

bchan@partners.org
To help end the worldwide AIDS epidemic by 2030, the Joint United Nations Programme on HIV/AIDS proposed a set of Fast Track or "90-90-90" targets to be achieved by 2020: the diagnosis of $90 \%$ of all people living with HIV (PLHIV), the provision of antiretroviral therapy (ART) to 90\% of those diagnosed, and the achievement of an undetectable viral load for $90 \%$ of those on treatment [1]. India, which has the third largest HIV epidemic in the world with 2.1 million PLHIV [2], has dramatically scaled-up access to ART over the last decade [3,4]. However, high rates of loss to HIV care suggest that India is far from achieving the 90-90-90 targets. In one cohort study in Andhra Pradesh, only 31\% of patients diagnosed with HIV ultimately achieved virologic suppression [5]. Similarly, the overall dropout rate at a large HIV care center in Tamil Nadu was 38 per 100 personyears [6]. Finally, in a nationwide cohort of men who have sex with men (MSM) and people who inject drugs (PID), only 10\% of HIV-infected cohort participants were on ART and virologically suppressed [7]. These estimates suggest that India is far from achieving the goal to eliminate AIDS. 
Little is known about the reasons for loss to HIV care in India after diagnosis. One study of loss to HIV care focused on clinical predictors such as $\mathrm{CD}^{+}$cell count and weight [8]. More recently, a study of Indian MSM and PID found that certain clinic-based factors, failure to disclose one's serostatus to others, and depressive symptoms were associated with decreased odds of linkage to HIV care [9]. Beyond this study, little is known about how psychosocial factors such as depression and HIV-related stigma affect loss to HIV care in India.

In other settings, particularly in sub-Saharan Africa, HIV-related stigma has been associated with psychological distress and depression [10,11] and poorer ART adherence among PLHIV [12,13]. Similarly, depression among PLHIV has been associated with increased transmission risk [14,15], greater CD4+ count declines [16,17], reduced ART adherence [18], and more rapid progression to AIDS and death $[17,19,20]$. Importantly, depression is a modifiable risk factor, as treatment of depression can result in reduced risk of HIV transmission [21] and improved ART adherence and virologic suppression [22]. Some studies have suggested that depression treatment should be combined with behavioral interventions to maximize improvements in HIV-related outcomes [23-25].

Compared to other low- and middle-income countries (LMICs) in which stigma and depression have been studied more extensively (eg, countries in sub-Saharan Africa), India features a markedly different socio-cultural environment and an epidemic that is highly concentrated among female sex workers, MSM, and PID [2]. As such, one cannot assume that findings on stigma and depression from other LMICs are applicable to the Indian context. Both HIV-related stigma [26-28] and depression [29-31] have been found to be highly prevalent among Indian PLHIV. Although some studies have shown an association between stigma and depression among Indian PLHIV [26,32,33], these studies included PLHIV both in and out of care at ART centers. If stigma and depression inhibit PLHIV from seeking care or contribute to loss to care after enrollment, then estimates based on mixed samples could potentially overstate the association between stigma and depression. Understanding the association between stigma and depression specifically among PLHIV entering into HIV care is particularly important, as this step in the HIV care continuum represents an opportunity to initiate interventions to attenuate their potential negative effects on HIV-related outcomes. If stigma and depression are closely correlated among PLHIV entering into care and initiating ART, then multi-faceted behavioral interventions targeting both depression as well as drivers of stigma may be needed to keep these PLHIV in care and virologically suppressed.

To help address these gaps in knowledge, we conducted a study of adults entering into care at a large HIV treatment center in Chennai, India. We hypothesized that internalized stigma (the internalization and acceptance of negative attitudes towards PLHIV and subsequent development of self-defacing beliefs [34]) and depression would be highly prevalent in this population and that internalized stigma and depression were highly correlated. The aims of this study were to 1) estimate the burden of internalized stigma and depression and 2) estimate the association between internalized stigma and depression.

\section{METHODS}

\section{Study setting and procedures}

This cross-sectional study was conducted at the Y.R. Gaitonde Centre for AIDS Research and Education (YRG CARE) in Chennai, India. YRG CARE is one of the largest private organizations providing HIV care in India, having treated over 20000 PLHIV since its founding in 1993. Chennai is the capital of Tamil Nadu state and one of the epicenters of the HIV epidemic in India [35]. As in other areas of India, the HIV epidemic in Tamil Nadu is concentrated, with an overall prevalence of $0.31 \%$ but a higher prevalence among female sex workers, MSM, and PID (between 2.4\% and 9.5\%) [2,36,37]. The majority of patients at YRG CARE come from Tamil Nadu and Andhra Pradesh states. Most patients at YRG CARE self-identify as heterosexual [29], as there are other organizations in Chennai which are perceived as specializing in care for sexual and gender minorities.

Patients were eligible for participation in the study if they were at least 18 years of age, HIV-infected, and newly entering into HIV care at YRG CARE between January 2015 and May 2016. Interviews were about 20 minutes long and were conducted by one of two female HIV counselors in the patient's preferred language (Tamil, Telugu, or English). All study materials were written in English, professionally translated into Tamil or Telugu, and back-translated to English to ensure fidelity to the original. Study staff obtained signed, or in case of illiteracy, thumbprint-marked informed consent documents from all participants. No remuneration was given. Potential participants were informed both verbally and through informed 
consent documents that refusal to participate would not impact the care that they would receive. Ethical approval for study procedures was obtained from the Institutional Review Boards of Fenway Health (Boston, Massachusetts, USA) and YRG CARE.

\section{Measures}

We administered questionnaires to PLHIV at their first clinical visit to YRG CARE after HIV diagnosis. To assess for depressive symptoms, we included the Patient Health Questionnaire-9 (PHQ-9) [38,39], which has been previously translated into Tamil and Telugu and validated in India [40,41]. Higher PHQ-9 scores (range, 0-27) signify greater levels of depression symptom severity. Study participants were considered to screen positive for probable depression if they either 1) returned a PHQ-9 score of greater than or equal to 10 or 2) endorsed the item "thoughts that [one] would be better off dead or of hurting [one]self in some way", as recommended by Kroenke and Spitzer [42].

To measure internalized stigma, we included the six-item Internalized AIDS-Related Stigma Scale (IARSS) [43]. We chose to focus on internalized stigma given a growing consensus that internalized stigma is an important predictor of HIV-related outcomes [44]. The IARSS is the most commonly used measure of internalized stigma in the literature, has been validated in multiple settings $[45,46]$, and is relatively brief compared to other commonly-used stigma scales such as the Berger HIV Stigma Scale [47] and the HIV/ AIDS Stigma Instrument - PLWA [48]. Two items relate to concerns about disclosure and four items relate to feelings of shame and/or self-hatred (Table 1). Responses were elicited on a binary scale (yes/no); scale scores represent the sum total of endorsed items (range 0-6). Like most HIV-related stigma scales, given that the degree of stigma is measured along a continuum, there is no clear prevalence cutoff for determining who is or is not "stigmatized". Although this was the first known use of the IARSS in India, questions with similar wording have been validated in India [28,32]. Further, we pilot-tested the questions on five Tamil and five Telugu speakers to ensure comprehensibility and face and content validity.

Sociodemographic variables of interest, collected as part of the standard YRG CARE patient questionnaire and clinical protocol, included gender, age, educational attainment, marital status (married vs other), employment status, rural/urban residence, language (Tamil/Telugu/other), sexual orientation ("homosexual," "heterosexual," or "bisexual"), alcohol use ("yes" vs "no" or "stopped"), and injection drug use (IDU) ("present use or previous use" vs "never use").

\section{Statistical analysis}

We used descriptive statistics to characterize the sample and to estimate the prevalence of probable depression, frequency of responses to the individual internalized stigma items, and mean PHQ-9 and IARSS scores. Responses were compared by gender using chi-square tests for categorical variables and t-tests for continuous variables. We then used Pearson correlation coefficient to estimate the correlation between internalized stigma (IARSS) and depressive symptoms (PHQ-9). We also dichotomized IARSS at the median value (0-2 vs 3-6) and compared probable depression by high and low internalized stigma score using a chi-square test.

Next, we used Poisson regression models [49,50], modified with robust estimates of variance $[51,52]$, to estimate the association between probable depression and internalized stigma (IARSS score). Following Zou [49], the incidence rate ratios were interpreted as risk ratios. We estimated both unadjusted and adjusted models, with the latter including sociodemographic variables as potential confounders. A statistically significant regression coefficient for IARSS was considered evidence that an association existed between internalized stigma and probable depression. As an alternative parameterization, we fitted a multivariable linear regression model with depressive symptoms (PHQ-9 score) as the outcome of interest.

To explore the possibility of bias from unobserved confounders of the relationship between internalized stigma and depressive symptoms, we used the sensitivity analysis detailed in Oster [53]. This procedure assumes a value for the maximum R-squared from a regression model and calculates a value for the relative degree of confounding by unobserved vs observed variables (the "delta") that would result in a regression coefficient equal to zero. We selected a maximum R-squared value of 1.3 multiplied by the Rsquared obtained in the multivariable linear regression model, as this is the level of robustness consistent with findings from randomized controlled trials [53].

\section{RESULTS}

524 persons entering into HIV care between January 2015 and May 2016 were enrolled into the study, including 304 men, 217 women, and 3 Hijra (transgender women). Because of the low number of Hijra 
Table 1. Characteristics of patients by gender

\begin{tabular}{|c|c|c|c|c|c|}
\hline Сharacteristic & $\begin{array}{c}\text { OverauL } \\
(n=521)\end{array}$ & $\begin{array}{l}\text { Women } \\
(\mathrm{N}=217)\end{array}$ & $\begin{array}{c}\text { Men } \\
(N=304)\end{array}$ & $\begin{array}{l}\text { T-IEST } / \chi^{2} \\
\text { STATISTIC }\end{array}$ & $\mathbf{P}$ \\
\hline \multicolumn{6}{|l|}{ Sociodemographic and clinical variables } \\
\hline Age, mean (SD), y & $39.6(8.8)$ & $37.1(7.6)$ & $41.3(9.1)$ & 5.50 & $<0.001 *$ \\
\hline Achieved more than primary education, $\%$ & 63.7 & 56.7 & 68.8 & 7.98 & $0.005^{*}$ \\
\hline Married, \% & 67.0 & 53.5 & 76.6 & 30.8 & $<0.001^{*}$ \\
\hline Employed, \% & 75.6 & 45.2 & 97.4 & 187.2 & $<0.001 *$ \\
\hline Urban residence, \% & 35.3 & 33.6 & 36.5 & 0.46 & 0.50 \\
\hline Tamil speaker, \% & 19.6 & 17.1 & 21.4 & 1.51 & 0.22 \\
\hline Telugu speaker, \% & 76.4 & 81.6 & 72.7 & 5.52 & $0.02 *$ \\
\hline Heterosexual, \% & 96.4 & 98.6 & 94.7 & 5.43 & $0.02 *$ \\
\hline Baseline CD4+ cell count, mean (SD) & $\begin{array}{c}347.7 \\
(493.3)\end{array}$ & $\begin{array}{c}396.8 \\
(345.7)\end{array}$ & $\begin{array}{c}314.0 \\
(571.1)\end{array}$ & 1.64 & 0.10 \\
\hline \multicolumn{6}{|l|}{ Substance use variables } \\
\hline Current alcohol use, \% & 14.0 & 0 & 24.0 & 60.6 & $<0.001^{*}$ \\
\hline Injection drug use, \% & 0.4 & 0 & 0.7 & 1.43 & 0.23 \\
\hline \multicolumn{6}{|l|}{ Depressive symptoms and internalized stigma } \\
\hline PHQ-9 score, mean (SD) & $2.8(3.3)$ & $2.8(3.2)$ & $2.7(3.4)$ & 0.41 & 0.68 \\
\hline Probable depression, \% & 9.6 & 10.6 & 8.9 & 0.43 & 0.51 \\
\hline IARSS score, mean (SD) & $2.4(1.7)$ & $2.3(1.6)$ & $2.5(1.7)$ & 1.46 & 0.15 \\
\hline It is difficult to tell people about my HIV infection, \% & 80.6 & 80.2 & 80.9 & 0.04 & 0.83 \\
\hline Being HIV positive makes me feel dirty, $\%$ & 28.6 & 26.3 & 30.3 & 0.99 & 0.32 \\
\hline I feel guilty that I am HIV positive, \% & 26.3 & 24.4 & 27.6 & 0.67 & 0.41 \\
\hline I am ashamed that I am HIV positive, \% & 13.4 & 10.6 & 15.5 & 2.57 & 0.11 \\
\hline I sometimes feel worthless because I am HIV positive, $\%$ & 15.6 & 12.0 & 18.1 & 3.60 & 0.06 \\
\hline I hide my HIV status from others, $\%$ & 77.7 & 76.0 & 79.0 & 0.62 & 0.43 \\
\hline
\end{tabular}

y - years, SD - standard deviation, PHQ-9 - Patient Health Questionnaire-9, IARSS - Internalized AIDS-Related Stigma Scale $* P<0.05$.

enrolled, we dropped these three observations from the analyses. No one refused entry into the study, although not all eligible patients may have been approached because of variable interviewer availability. Participant characteristics are stratified by gender in Table 1. 502 (96\%) self-reported as heterosexual. The mean age was 40 years (standard deviation (SD) 9 years). Prevalence of self-reported IDU was low $(<1 \%)$. Telugu was the primary language of $76 \%$ of participants, with a majority of the remaining participants reporting Tamil as their primary language. The mean baseline $\mathrm{CD}^{+}$cell count (available for 394 participants) was 348 cells $/ \mathrm{mm}^{3}$ (SD, 493).

The prevalence of probable depression was $10 \%$ and the mean PHQ-9 score was 2.8 (SD, 3.3). The scale reliability coefficient for the PHQ-9 was 0.80. The mean IARSS score was 2.4 (SD, 1.7). 427 (82\%) participants endorsed at least one of the six IARSS items and $33(6 \%)$ of participants endorsed all six IARSS items. The two IARSS items most commonly endorsed were related to concerns about disclosure: "I hide my HIV status from others" (78\%) and "It is difficult to tell people about my HIV infection" (81\%). The scale reliability coefficient for the IARSS was 0.79 . The Pearson correlation coefficient between IARSS and the PHQ-9 was 0.47 , indicating a correlation of moderate magnitude. $23 \%$ (44/192) of participants with an IARSS score of 3-6 screened positive for depression, compared to only $2 \%(6 / 329)$ of participants with an IARSS score of $0-2\left(\chi^{2}=62.2, P<0.001\right)$.

In unadjusted analyses (Table 2), younger age, urban residence, being a Tamil speaker, current alcohol use, and higher IARSS score were associated with an increased risk of probable depression. After multivariable adjustment (Table 2), being a Tamil speaker and IARSS score were associated with increased risk of probable depression. The adjusted relative risk ratio for IARSS was 1.83 (95\% confidence interval (CI) $1.56-$ 2.14), indicating a nearly two times higher risk of screening positive for depression for each additional point on the IARSS. Turning next to the multivariable linear regression model with continuous depressive symptom severity (PHQ-9 score) as the outcome of interest, we observed a statistically significant positive association between IARSS and depressive symptoms (adjusted $b=0.91 ; 95 \%$ CI $0.76-1.06$ ). Put another way, we found an approximate increase in the PHQ-9 score of 0.9 for every additional point on the IARSS. 
Table 2. Unadjusted and adjusted risk ratios and $95 \%$ confidence intervals for variables associated with probable depression

\begin{tabular}{lcc} 
Variabif & Unadusted RisK RATIO (95\% CI) & Adjusted Risk RATIO (95\% CI) \\
Female (vs other) & $0.838(0.494-1.422)$ & $0.510(0.248-1.051)$ \\
\hline Age, per 10 year & $0.725(0.544-0.964) *$ & $0.802(0.619-1.037)$ \\
\hline Achieved more than primary education (vs other) & $1.012(0.584-1.753)$ & $1.094(0.631-1.900)$ \\
\hline Married (vs unmarried) & $0.681(0.400-1.158)$ & $1.037(0.604-1.780)$ \\
\hline Employed (vs unemployed) & $0.917(0.503-1.672)$ & $0.996(0.511-1.942)$ \\
\hline Urban residence (vs rural) & $2.150(1.270-3.641)^{*}$ & $1.298(0.772-2.182)$ \\
\hline Tamil speaker (vs other) & $2.739(1.623-4.621)^{* *}$ & $1.986(1.196-3.297)^{*}$ \\
\hline Current alcohol use & $2.156(1.205-3.859)^{*}$ & $1.807(0.954-3.422)$ \\
\hline IARSS score & $1.907(1.647-2.208)^{*}$ & $1.828(1.559-2.143)^{* *}$ \\
\hline
\end{tabular}

CI - confidence interval, IARSS - Internalized AIDS-Related Stigma Scale

${ }^{*} P<0.05$ and $* * P<0.001$.

In the sensitivity analysis exploring the robustness of the relationship between IARSS and depressive symptoms (PHQ-9 score), we assumed a maximum R-squared value of 0.267 (the R-squared obtained in the multivariable regression model) $\times 1.3=0.347$, following the procedures described by Oster [53] Using this maximum R-squared value, we calculated a delta of 2.34 , indicating that confounding by unobserved variables would need to be more than twice as important as confounding by the observed variables in the regression model to generate a regression coefficient for IARSS equal to zero.

\section{DISCUSSION}

In this sample of newly diagnosed PLHIV entering into HIV care in southern India, we found a high prevalence of internalized stigma despite a relatively low prevalence of probable depression. The prevalence of probable depression in this study was $10 \%$, which was lower than prior studies of Indian PLHIV $[30,31,54]$. The reasons for this lower prevalence of probable depression are unclear. One possible explanation may relate to a temporal trend in rising mean $C D 4^{+}$cell count among patients presenting to YRG CARE, from approximately 160 in 2006 (unpublished data) to 347 in this cohort. In one study of Ugandan PLHIV from 2005-2012, there was a decline over time in mean depression symptom severity scores at ART initiation, a trend that appeared to be explained by improved physical health scores over time [55].

In contrast, we found that internalized stigma was reported commonly, with more than four-fifths of respondents endorsing at least one measure of internalized stigma. While relatively few respondents felt "guilty," "dirty," "ashamed," or "worthless" because of their serostatus, approximately four-fifths of respondents endorsed concerns about serostatus disclosure. This suggests that while most Indian PLHIV may not regard stigmatizing attitudes towards PLHIV as valid, they fear the consequences of disclosure and anticipate rejection and isolation from others [56]. This pattern is consistent with prior studies from India, which have found that PLHIV anticipate stigma much more frequently than they actually experience instances of enacted stigma [28]. Of note, while others have contended that the consequences of disclosure may be particularly harsh for Indian women with HIV, who may face financial hardship and rejection at the hands of husbands' families [57,58], we did not find significant gender differences in IARSS score or in responses to the items on serostatus disclosure. This contrasts with prior research with Indian PLHIV, which has found higher internalized stigma scores among men, primarily driven by gender differences in feelings of shame or guilt $[27,33]$.

We also found that internalized stigma and depression were closely correlated. Nearly a quarter of participants with an IARSS score of 3-6, but only 2\% with an IARSS score of 0-2, screened positive for depression. In a modified Poisson regression model adjusted for sociodemographic variables, we found that each additional point on the IARSS was associated with a nearly two times higher risk of probable depression. Our sensitivity analysis demonstrated that this finding was fairly robust, in that confounding by unobserved variables would need to be more than twice as important as confounding by observed variables to generate a regression coefficient for IARSS equal to zero. A person living with HIV who has internalized and accepted negative attitudes towards PLHIV as valid may suffer from self-hatred [59], hopelessness [60], isolation, and emotional distress [61]. Furthermore, a person living with HIV who harbors concerns about disclosure may lack social support and affirmation from family and friends. Fears of disclosure among Indian PLHIV have been linked to depressive symptoms [28] as well as poor outcomes such as failure to link to HIV care [9]. 
Further study is needed to determine whether depression and internalized stigma are associated with poor HIV treatment outcomes such as loss to care and lack of virologic suppression in India, and in particular whether the combination of depression and stigma is particularly deleterious. Such studies would highlight the importance of screening PLHIV for internalized stigma and depression at entry into care and ultimately reveal targets for policymakers to forestall loss from the HIV care continuum. For example, if fears of disclosure and the potential consequences of social rejection and economic incapacity are driving depressive symptoms and poor HIV-related outcomes, then interventions to help PLHIV safely disclose their serostatus or to bolster their economic capacity may help to keep PLHIV in care and on treatment.

There are several limitations to this study. First, as the study was conducted at a single HIV care center in India, the findings may not be generalizable to the entire country. In particular, given the high proportion of patients at YRG CARE who self-identify as heterosexual (although this number may be affected by disclosure bias), our findings may not be applicable to sexual and gender minorities. Nevertheless, we hope that our results will spur similar research among sexual and gender minorities and PLHIV who seek care in other parts of India and in the public sector. In addition, the type of private, multi-service program available at YRG CARE can be found in other cities in India as well as other Asian countries. Second, although the PHQ-9 can be used to identify persons with symptoms indicative of probable depression, we did not have access to data on DSM-consistent diagnoses of depressive disorders. However, the PHQ-9 has been shown to have good accuracy in diagnosing major depressive disorder in India [40,41]. Third, the IARSS, like other stigma scales, is limited by multiple factors, including 1) the difficulties inherent in operationalizing HIV-related stigma, a concept for which a consensus definition has been elusive $[44,62]$, 2) the inability to draw conclusions on the "prevalence" of internalized stigma as no validated cut-off exists, and 3) the potential conceptual overlap between IARSS and other mental health measures such as the PHQ-9. While we acknowledge that the IARSS may not assess all aspects of internalized stigma among PLHIV and that we cannot comment on an exact "prevalence" of internalized stigma in our sample, our findings suggest an association between depression and the dimensions of internalized stigma in India captured by the IARSS-in particular, fears of serostatus disclosure and self-hatred. Finally, we encountered limitations in the use of the existing YRG CARE questionnaire for correlates of interest (in particular, the dichotomous nature of the alcohol use variable). Further research is needed to more precisely measure these variables, including measures of problem drinking, to understand possible associations with depression among Indian PLHIV.

In summary, we found that PLHIV entering into HIV care at a large ART center in southern India commonly endorsed fears of serostatus disclosure and that stigma and depression were closely correlated. Although there is likely a bidirectional relationship between stigma and depression among Indian PLHIV, as has been demonstrated in other LMICs $[10,11]$, more study is needed to characterize the linkages between HIV-related stigma and depression in India specifically and the impact of these conditions on HIVrelated outcomes. Depression and stigma may provide important targets for policymakers seeking to keep Indian PLHIV alive, in care, and on effective treatment.

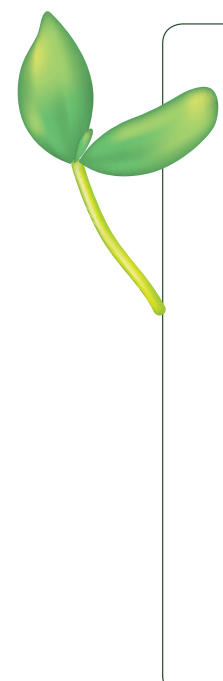

Acknowledgments: We are grateful to the many staff members of the Y.R. Gaitonde Centre for AIDS Research and Education who participated in this project.

Funding: This work was supported by Harvard Catalyst|The Harvard Clinical and Translational Science Center (National Center for Research Resources and the National Center for Advancing Translational Sciences, National Institutes of Health Award KL2 TR001100, an appointed KL2/Catalyst Medical Research Investigator Training award) and NIH K23MH110338 (Chan); NIH P30AI060354 (Mayer); unrestricted research grants from Merck, Gilead, and Bristol Meyers Squibb (Mayer); and NIH K23MH096620 (Tsai).

Authorship contribution: BTC contributed to conceptualization of the study, creation of study materials, and preparation of the first draft of the manuscript. AP, LP, VM, and EC contributed to acquiring data and assessing data quality. NK and KHM contributed to editing the article and data interpretation. ACT contributed to conceptualization of the study, data analysis and interpretation, and editing the article. All authors contributed to the analysis and writing of the final draft and have approved the final manuscript.

Competing interests: The authors have completed the Unified Competing Interest form at www.icmje.org/ coi_disclosure.pdf (available on request from the corresponding author) and declare no conflict of interest. 
1 Joint United Nations Programme on HIV AIDS. 90-90-90: An ambitious treatment target to help end the AIDS epidemic. 2014. http://www.unaids.org/sites/default/files/media_asset/90-90-90_en_0.pdf. Accessed: 9 May 2016.

2 National AIDS Control Organisation. India HIV estimations 2015: Technical report. 2015. http://www.naco.gov.in/upload/2015\%20MSLNS/HSS/India\%20HIV\%20Estimations\%202015.pdf. Accessed: 13 May 2016.

3 Srikantiah P, Ghidinelli M, Bachani D, Chasombat S, Daoni E, Mustikawati DE, et al. Scale-up of national antiretroviral therapy programs: progress and challenges in the Asia Pacific region. AIDS. 2010;24 Suppl 3:S62-71. Medline:20926930 doi:10.1097/01.aids.0000390091.45435.ea

4 Kumarasamy N, Pendse R. Long term impact of antiretroviral therapy-can we end HIV epidemic, the goal beyond 2015. Indian J Med Res. 2014;140:701-3. Medline:25758565

5 Alvarez-Uria G, Pakam R, Midde M, Naik PK. Entry, retention, and virological suppression in an HIV cohort study in India: Description of the cascade of care and implications for reducing hiv-related mortality in low- and middle-income countries. Interdiscip Perspect Infect Dis. 2013;2013:384805. Medline:23935613 doi:10.1155/2013/384805

6 Blutinger EJ, Solomon S, Srikrishnan AK, Thamburaj E, Kumarasamy N, Balakrishnan P, et al. Dropout from care among HIV-infected patients enrolled in care at a tertiary HIV care center in Chennai, India. AIDS Care. 2014;26:1500-5. Medline:25011519 doi:10.1080/09540121.2014.934654

7 Mehta SH, Lucas GM, Solomon S, Srikrishnan AK, McFall AM, Dhingra N, et al. HIV care continuum among men who have sex with men and persons who inject drugs in India: Barriers to successful engagement. Clin Infect Dis. 2015;61:173241. Medline:26251048

8 Allam RR, Murhekar MV, Bhatnagar T, Uthappa CK, Chava N, Rewari BB, et al. Survival probability and predictors of mortality and retention in care among patients enrolled for first-line antiretroviral therapy, Andhra Pradesh, India, 20082011. Trans R Soc Trop Med Hyg. 2014;108:198-205. Medline:24627424 doi:10.1093/trstmh/tru025

9 McFall AM, Mehta SH, Srikrishnan AK, Lucas GM, Vasudevan CK, Celentano DD, et al. Getting to 90: linkage to HIV care among men who have sex with men and people who inject drugs in India. AIDS Care. 2016;28:1230-9. Medline:27054274 doi:10.1080/09540121.2016.1168915

10 Simbayi LC, Kalichman S, Strebel A, Cloete A, Henda N, Mqeketo A. Internalized stigma, discrimination, and depression among men and women living with HIV/AIDS in Cape Town, South Africa. Soc Sci Med. 2007;64:1823-31. Medline: 17337318 doi:10.1016/j.socscimed.2007.01.006

11 Tsai AC, Bangsberg DR, Frongillo EA, Hunt PW, Muzoora C, Martin JN, et al. Food insecurity, depression and the modifying role of social support among people living with HIV/AIDS in rural Uganda. Soc Sci Med. 2012;74:2012-9. Medline:22513248 doi:10.1016/j.socscimed.2012.02.033

12 Katz IT, Ryu AE, Onuegbu AG, Psaros C, Weiser SD, Bangsberg DR, et al. Impact of HIV-related stigma on treatment adherence: systematic review and meta-synthesis. J Int AIDS Soc. 2013;16:18640. Medline:24242258 doi:10.7448/ IAS.16.3.18640

13 Boyer S, Clerc I, Bonono C-R, Marcellin F, Bilé P-C, Ventelou B. Non-adherence to antiretroviral treatment and unplanned treatment interruption among people living with HIV/AIDS in Cameroon: Individual and healthcare supply-related factors. Soc Sci Med. 2011;72:1383-92. Medline:21470734 doi:10.1016/j.socscimed.2011.02.030

14 Olley BO, Seedat S, Stein DJ. Persistence of psychiatric disorders in a cohort of HIV/AIDS patients in South Africa: a 6-month follow-up study. J Psychosom Res. 2006;61:479-84. Medline:17011355 doi:10.1016/j.jpsychores.2006.03.010

15 Meade CS, Sikkema KJ. HIV risk behavior among adults with severe mental illness: a systematic review. Clin Psychol Rev. 2005;25:433-57. Medline:15914265 doi:10.1016/j.cpr.2005.02.001

16 Burack JH, Barrett DC, Stall RD, Chesney MA, Ekstrand ML, Coates TJ. Depressive symptoms and CD4 lymphocyte decline among HIV-infected men. JAMA. 1993;270:2568-73. Medline:7901433 doi:10.1001/jama.1993.03510210054027

17 Ickovics JR, Hamburger ME, Vlahov D, Schoenbaum EE, Schuman P, Boland RJ, et al. Mortality, CD4 cell count decline, and depressive symptoms among HIV-seropositive women: longitudinal analysis from the HIV Epidemiology Research Study. JAMA. 2001;285:1466-74. Medline:11255423 doi:10.1001/jama.285.11.1466

18 Holzemer WL, Corless IB, Nokes KM, Turner JG, Brown MA, Powell-Cope GM, et al. Predictors of self-reported adherence in persons living with HIV disease. AIDS Patient Care STDS. 1999;13:185-97. Medline:10375267 doi:10.1089/ apc. 1999.13.185

19 Antelman G, Kaaya S, Wei R, Mbwambo J, Msamanga GI, Fawzi WW, et al. Depressive symptoms increase risk of HIV disease progression and mortality among women in Tanzania. J Acquir Immune Defic Syndr. 2007;44:470-7. Medline:17179766 doi:10.1097/QAI.0b013e31802f1318

20 Cook JA, Grey D, Burke J, Cohen MH, Gurtman AC, Richardson JL, et al. Depressive symptoms and AIDS-related mortality among a multisite cohort of HIV-positive women. Am J Public Health. 2004;94:1133-40. Medline:15226133 doi:10.2105/AJPH.94.7.1133

21 Sikkema KJ, Watt MH, Drabkin AS, Meade CS, Hansen NB, Pence BW. Mental health treatment to reduce HIV transmission risk behavior: a positive prevention model. AIDS Behav. 2010;14:252-62. Medline:20013043 doi:10.1007/s10461009-9650-y

22 Tsai AC, Weiser SD, Petersen ML, Ragland K, Kushel MB, Bangsberg DR. A marginal structural model to estimate the causal effect of antidepressant medication treatment on viral suppression among homeless and marginally housed persons with HIV. Arch Gen Psychiatry. 2010;67:1282-90. Medline:21135328 doi:10.1001/archgenpsychiatry.2010.160

23 Tsai AC, Karasic DH, Hammer GP, Charlebois ED, Ragland K, Moss AR, et al. Directly observed antidepressant medication treatment and HIV outcomes among homeless and marginally housed HIV-positive adults: a randomized controlled trial. Am J Public Health. 2013;103:308-15. Medline:22720766 doi:10.2105/AJPH.2011.300422 
24 Tsai AC, Mimiaga MJ, Dilley JW, Hammer GP, Karasic DH, Charlebois ED, et al. Does effective depression treatment alone reduce secondary HIV transmission risk? Equivocal findings from a randomized controlled trial. AIDS Behav. 2013;17:2765-72. Medline:23975476 doi:10.1007/s10461-013-0600-3

25 Pence BW, Gaynes BN, Adams JL, Thielman NM, Heine AD, Mugavero MJ, et al. The effect of antidepressant treatment on HIV and depression outcomes: results from a randomized trial. AIDS. 2015;29:1975-86. Medline:26134881 doi:10.1097/QAD.0000000000000797

26 Charles B, Jeyaseelan L, Pandian AK, Sam AE, Thenmozhi M, Jayaseelan V. Association between stigma, depression and quality of life of people living with HIV/AIDS (PLHA) in South India - a community based cross sectional study. BMC Public Health. 2012;12:463. Medline:22720691 doi:10.1186/1471-2458-12-463

27 Malavé S, Ramakrishna J, Heylen E, Bharat S, Ekstrand ML. Differences in testing, stigma, and perceived consequences of stigmatization among heterosexual men and women living with HIV in Bengaluru, India. AIDS Care. 2014;26:396403. Medline:23869716 doi:10.1080/09540121.2013.819409

28 Steward WT, Herek GM, Ramakrishna J, Bharat S, Chandy S, Wrubel J, et al. HIV-related stigma: adapting a theoretical framework for use in India. Soc Sci Med. 2008;67:1225-35. Medline:18599171 doi:10.1016/j.socscimed.2008.05.032

29 Chan BT, Pradeep A, Prasad L, Murugesan V, Chandrasekaran E, Kumarasamy N, et al. Prevalence and correlates of psychosocial conditions among people living with HIV in southern India. AIDS Care. 2017;29:746-50. Medline:27643850 doi:10.1080/09540121.2016.1231887

30 Khan MA, Sehgal A. Clinico-epidemiological and Socio-behavioral Study of People Living with HIV/AIDS. Indian J Psychol Med. 2010;32:22-8. Medline:21799555 doi:10.4103/0253-7176.70523

31 Nebhinani N, Mattoo SK, Wanchu A. Psychiatric morbidity in HIV-positive subjects: a study from India. J Psychosom Res. 2011;70:449-54. Medline:21511075 doi:10.1016/j.jpsychores.2010.09.021

32 Jeyaseelan L, Kumar S, Mohanraj R, Rebekah G, Rao D, Manhart LE. Assessing HIV/AIDS stigma in south India: validation and abridgement of the Berger HIV Stigma scale. AIDS Behav. 2013;17:434-43. Medline:22246514 doi:10.1007/ s10461-011-0128-3

33 Zelaya CE, Sivaram S, Johnson SC, Srikrishnan AK, Suniti S, Celentano DD. Measurement of self, experienced, and perceived HIV/AIDS stigma using parallel scales in Chennai, India. AIDS Care. 2012;24:846-55. Medline:22272891 doi:1 $0.1080 / 09540121.2011 .647674$

34 Link BG, Cullen FT, Struening E, Shrout PE, Dohrenwend BP. A Modified Labeling Theory Approach to Mental Disorders: An Empirical Assessment. Am Sociol Rev. 1989;54:400. doi:10.2307/2095613

35 Kumarasamy N, Solomon S, Peters E, Amalraj RE, Purnima M, Ravikumar B, et al. Antiretroviral drugs in the treatment of people living with human immunodeficiency virus: experience in a south Indian tertiary referral centre. J Assoc Physicians India. 2000;48:390-3. Medline:11273171

36 World Bank. HIV/AIDS in India. 2012. http://www.worldbank.org/en/news/feature/2012/07/10/hiv-aids-india. Accessed: 27 July 2014.

37 National AIDS Control Organisation. HIV Sentinel Surveillance 2014-15: A Technical Brief. http://www.naco.gov.in/sites/ default/files/HIV_Sentinel_Surveillance_report.pdf. Accessed: 26 April 2017.

38 Kroenke K, Spitzer RL, Williams JB. The PHQ-9: validity of a brief depression severity measure. J Gen Intern Med. 2001;16:606-13. Medline:11556941 doi:10.1046/j.1525-1497.2001.016009606.x

39 Monahan PO, Shacham E, Reece M, Kroenke K, Ong'or WO, Omollo O, et al. Validity/reliability of PHQ-9 and PHQ-2 depression scales among adults living with HIV/AIDS in western Kenya. J Gen Intern Med. 2009;24:189-97. Medline:19031037 doi:10.1007/s11606-008-0846-z

40 Ganguly S, Samanta M, Roy P, Chatterjee S, Kaplan DW, Basu B. Patient health questionnaire-9 as an effective tool for screening of depression among Indian adolescents. J Adolesc Health. 2013;52:546-51. Medline:23299020 doi:10.1016/j. jadohealth.2012.09.012

41 Kochhar PH, Rajadhyaksha SS, Suvarna VR. Translation and validation of brief patient health questionnaire against DSM IV as a tool to diagnose major depressive disorder in Indian patients. J Postgrad Med. 2007;53:102-7. Medline:17495375 doi:10.4103/0022-3859.32209

42 Kroenke K, Spitzer RL. The PHQ-9: A New Depression Diagnostic and Severity Measure. Psychiatr Ann. 2002;32:50915. doi:10.3928/0048-5713-20020901-06

43 Kalichman SC, Simbayi LC, Cloete A, Mthembu PP, Mkhonta RN, Ginindza T. Measuring AIDS stigmas in people living with HIV/AIDS: the Internalized AIDS-Related Stigma Scale. AIDS Care. 2009;21:87-93. Medline:19085224 doi:10.1080/09540120802032627

44 Earnshaw VA, Chaudoir SR. From conceptualizing to measuring HIV ytigma: A review of HIV stigma mechanism measures. AIDS Behav. 2009;13:1160-77. Medline:19636699 doi:10.1007/s10461-009-9593-3

45 Tsai AC, Weiser SD, Steward WT, Mukiibi NFB, Kawuma A, Kembabazi A, et al. Evidence for the reliability and validity of the internalized AIDS-related stigma scale in rural Uganda. AIDS Behav. 2013;17:427-33. Medline:22869104 doi:10.1007/s10461-012-0281-3

46 Pantelic M, Shenderovich Y, Cluver L, Boyes M. Predictors of internalised HIV-related stigma: a systematic review of studies in sub-Saharan Africa. Health Psychol Rev. 2015;9:469-90. Medline:25559431 doi:10.1080/17437199.2014.996243

47 Berger BE, Ferrans CE, Lashley FR. Measuring stigma in people with HIV: psychometric assessment of the HIV stigma scale. Res Nurs Health. 2001;24:518-29. Medline:11746080 doi:10.1002/nur.10011

48 Holzemer WL, Uys LR, Chirwa ML, Greeff M, Makoae LN, Kohi TW, et al. Validation of the HIV/AIDS Stigma Instrument - PLWA (HASI-P). AIDS Care. 2007;19:1002-12. Medline:17851997 doi:10.1080/09540120701245999 
49 Zou G. A modified poisson regression approach to prospective studies with binary data. Am J Epidemiol. 2004;159:7026. Medline:15033648 doi:10.1093/aje/kwh090

50 Yelland LN, Salter AB, Ryan P. Performance of the modified Poisson regression approach for estimating relative risks from clustered prospective data. Am J Epidemiol. 2011;174:984-92. Medline:21841157 doi:10.1093/aje/kwr183

51 Huber PJ. The behavior of maximum likelihood estimates under nonstandard conditions. In: Proceedings of the Fifth Berkeley Symposium on Mathematical Statistics and Probability. Berkeley, CA: 1967. pp. 221-233.

52 White H. A Heteroskedasticity-consistent covariance matrix estimator and a direct test for heteroskedasticity. Econometrica. 1980;48:817-38. doi:10.2307/1912934

53 Oster E. Unobservable selection and coefficient stability: theory and evidence. J Bus Econ Stat. 2016; Epub ahead of print. doi:10.1080/07350015.2016.1227711

54 Talukdar A, Ghosal MK, Sanyal D, Sengupta Talukdar P, Guha P, Guha SK, et al. Determinants of quality of life in HIVinfected patients receiving highly active antiretroviral treatment at a Medical College ART Center in Kolkata, India. J Int Assoc Provid AIDS Care. 2013;12:284-90. Medline:22628368 doi:10.1177/1545109712445924

55 Chan BT, Weiser SD, Boum Y, Haberer JE, Kembabazi A, Hunt PW, et al. Declining prevalence of probable depression among patients presenting for antiretroviral therapy in rural uganda: The Role of early treatment initiation. AIDS Behav. 2015;19:19-26. Medline:24788780 doi:10.1007/s10461-014-0785-0

56 Link BG. Understanding labeling effects in the area of mental disorders: An assessment of the effects of expectations of rejection. Am Sociol Rev. 1987;52:96-112. doi:10.2307/2095395

57 Pallikadavath S, Garda L, Apte H, Freedman J, Stones RW. HIV/AIDS in rural India: context and health care needs. J Biosoc Sci. 2005;37:641-55. Medline:16174351 doi:10.1017/S0021932004006893

58 Chakrapani V, Newman PA, Shunmugam M, Kurian AK, Dubrow R. Barriers to free antiretroviral treatment access for female sex workers in Chennai, India. AIDS Patient Care STDS. 2009;23:973-80. Medline:19821725 doi:10.1089/ apc.2009.0035

59 Rankin WW, Brennan S, Schell E, Laviwa J, Rankin SH. The stigma of being HIV-positive in Africa. PLoS Med. $2005 ; 2$ :e247. Medline:16008508 doi:10.1371/journal.pmed.0020247

60 Lee RS, Kochman A, Sikkema KJ. Internalized stigma among people living with HIV-AIDS. AIDS Behav. 2002;6:309-19. doi:10.1023/A:1021144511957

61 Crandall CS, Coleman R. AIDS-related stigmatization and the disruption of social relationships. J Soc Pers Relat. 1992;9:163-77. doi:10.1177/0265407592092001

62 Deacon H. Towards a sustainable theory of health-related stigma: lessons from the HIV/AIDS literature. J Community Appl Soc Psychol. 2006;16:418-25. doi:10.1002/casp.900 